\title{
Success rates in the correction of astigmatism with toric and spherical soft contact lens fittings
}

This article was published in the following Dove Press journal:

Clinical Ophthalmology

19 August 2010

Number of times this article has been viewed

\section{Sevda Aydin Kurna \\ Tomris Șengör \\ Murat Ün \\ Suat Aki}

Fatih Sultan Mehmet Education and Research Hospital, Ophthalmology Clinics, İstanbul, Turkey
Correspondence: Sevda Aydin Kurna Ömerli Park 2 Sit, 2 Ömerli-Çekmeköy, İstanbul,Turkey

Tel +902165783000 ext 3632

Fax +902165783099

Email sevdaydin@yahoo.com
Objectives: To evaluate success rates in the correction of astigmatism with toric and spherical soft contact lens fitting.

Methods: 30 patients with soft toric lenses having more than $1.25 \mathrm{D}$ of corneal astigmatism (25 eyes; Group A) or having 0.75-1.25 D of corneal astigmatism (22 eyes; Group B ) and 30 patients with soft spheric lenses having $0.75-1.25 \mathrm{D}$ of corneal astigmatism (28 eyes; Group C) or less than 0.75 D of corneal astigmatism (23 eyes; Group D ) were included in the study. Corrected and uncorrected monocular visual acuity measurement with logMAR, biomicroscopic properties, autorefractometry and corneal topography were performed for all patients immediately before and at least 20 minutes after the application of contact lenses. Success of contact lens fitting was evaluated by three parameters: astigmatic neutralization, visual success, and retinal deviation.

Results: After soft toric lens application, spheric dioptres, cylindric and keratometric astigmatism, and retinal deviation decreased significantly in Groups A and B $(P<0.05)$. In Group C, spheric dioptres and retinal deviation decreased $(P<0.05)$, while cylindric and keratometric astigmatism did not change significantly $(P>0.05)$. In Group D, spheric dioptres, retinal deviation, and cylindric astigmatism decreased $(P<0.05)$. Keratometric astigmatism did not change significantly $(P>0.05)$ and astigmatic neutralization even increased.

Conclusions: Visual acuity and residual spherical equivalent refraction remained between tolerable limits with the use of toric and spheric contact lenses. Spherical lenses failed to mask corneal toricity during topography, while toric lenses caused central neutralization and decrease in corneal cylinder in low and moderate astigmatic eyes.

Keywords: astigmatism, soft toric lenses, soft spheric lenses, spherical equivalent refraction, surface topography

\section{Introduction}

The goal of soft contact lens application is to achieve excellent vision with overall lens comfort. Astigmats represent approximately one-third of potential contact lens wearers. The proportion of toric soft lenses prescribed has been much lower than this. ${ }^{1,2}$ For astigmatic eyes, soft spheric (42.5\%), soft toric $(21.9 \%)$, and rigid gas permeable (35.6\%) lenses have been preferred in the previous studies. ${ }^{3}$ Morgan et al have reported a doubling in the use of toric soft lenses to $27 \%$ of new fits over a five year period In the UK. ${ }^{4}$

Soft spheric contact lenses with uniform thickness will contour the corneal astigmatism, resulting in an astigmatic front surface of the soft contact lens. Contact lens thickness can affect lens flexure and astigmatic neutralization. Central thicknesses of 
the lenses used today are considered to have insignificant resistance to bending. ${ }^{5}$ To correct corneal astigmatism, toric soft contact lenses with non-uniform thickness profiles are designed and produced using different techniques. ${ }^{6,7}$

There have been many developments in toric lens technology and modeling, giving clinicians the advantages of larger parameter ranges, frequent displacement, and improved clinical performance. No significant differences have been observed with respect to contrast sensitivity thresholds, Snellen acuity thresholds, or subjective preferences between spectacles and toric hydrogel lenses. ${ }^{8}$ Disposable toric contact lenses provide good visual acuity and are considered to be appropriate for correcting astigmatism. ${ }^{9}$ Nevertheless, a recent wearer survey showed the high levels of lens performance expected by toric lens wearers were not being achieved, especially when comparing comfort and vision ratings. ${ }^{10}$

Adaptation to corneal astigmatism depends on the ratio of astigmatism to the total refractive error. However, tolerance of astigmatism may increase in correlation with the increased spheric error. ${ }^{6}$ A question in correcting spherocylindric refractive error with soft toric and soft spheric lenses is whether the increase in visual acuity is due to the neutralisation of refraction, or that the higher tolerance of patients is making us think that we are successful. Theoretically, soft toric lenses should totally neutralise the corneal astigmatism, while spheric soft lenses may partially neutralize it, mainly because of the thickness of these lenses. Since topographic maps may show changes on the front surface of a soft contact lens, corneal topography may be beneficial in assessing the degree of effectiveness of spherical and toric contact lenses.

In our study, the purpose was to determine how successful we are in correcting spherocylindric refractive errors with soft toric and spheric lenses by objective and subjective criteria, and to compare these two types of lenses in low and moderate astigmatic cases.

\section{Materials and methods}

30 patients with soft toric lenses having more than 1.25 D of corneal astigmatism (25 eyes; Group A ) or having
0.75-1.25 D of corneal astigmatism (22 eyes; Group B ) and 30 patients with soft spheric lenses having $0.75-1.25 \mathrm{D}$ of corneal astigmatism (28 eyes; Group C) or less than $0.75 \mathrm{D}$ of corneal astigmatism (23 eyes; Group D ) were included in the study. Specifications of the toric and spherical contact lenses used are summarized in Table 1.

Patients willing to use contact lenses were chosen and those having ocular surface diseases or functional deficit of the tear film were excluded. Written, informed consent was provided from the patients. Corrected and uncorrected monocular visual acuity measurement with $\log$ MAR, biomicroscopic properties, autorefractometry and corneal topography with a placido disk-based corneal mapping system, transferring data to color mapping software measurements (Topcon KR 7000P, Topcon Corporation, Tokyo, Japan) were performed for all patients immediately before and at least 20 minutes after the application of contact lenses.

Optimum fitting for corneal coverage, horizontal and vertical centration and movement was achieved, as suggested by Young, ${ }^{11}$ using spherical lenses fitted to the mean spherical equivalent prescription. The scribe marks on the toric soft lenses were located between $0-10^{\circ}$ from the lens marking location after lens settling.

During the biomicroscopic evaluation, centralization, axial rotation, and deposits on the contact lenses were noted. The orientation of the lens was assessed with the slit lamp and the rotations were recorded with reference to lazer markings.

Success of contact lens fitting was evaluated by three parameters:

1. Astigmatic neutralization: In order to compare the effective neutralization of different diopters of corneal astigmatism, residual astigmatism after contact lens application was divided by the initial or total corneal astigmatism determined before contact lens application, and expressed as a percentage using the the following formula: residual/total cylinder $\%$.

2. Visual success: Visual acuity, corrected with contact lenses and glasses in $\log$ MAR, was compared. Difference in visual acuity less than 2.0 lines was accepted

Table I Specifications of toric and spherical contact lenses

\begin{tabular}{llllll}
\hline Group As-B & No. & Central thick $(\mathbf{m m})$ & Groups C-D & No. & Central thick (mm) \\
\hline $\begin{array}{l}\text { Focus }^{\circledR} \text { toric (Ciba) } \\
\text { Freshlook }^{\circledR} \text { toric }\end{array}$ & 13 & 0.14 & Focus visitint (Ciba) & 13 & 0.1 \\
$\begin{array}{l}\text { (Wesley Jessen) } \\
\text { SL-66 toric (Bausch }\end{array}$ & 19 & 0.11 & Freshlook LT (Wesley Jessen) & 19 & 0.08 \\
and Lomb) & 15 & 0.19 & SL-66 (Bausch and Lomb) & 20 & 0.1 \\
\hline
\end{tabular}


as successful application, and the success rate was determined subjectively.

3. Mean retinal deviation (absolute spherical equivalent fraction): To simplify the combined effect of spherıc and cylindirical power, residual refractive errors of the patients based on autorefractometry were formulated as described by Poyor et al. ${ }^{12}$ Deviation was calculated by taking the mean of the absolute values of the principal meridians in diopters. Axial rotation was not taken into consideration.

Mean retinal deviation values were calculated for each of the groups before and after contact lens application and termed "total" and "residual" retinal deviations respectively. Residual retinal deviation values less than $0.50 \mathrm{D}$ were accepted as successful. Success rates were evaluated for each group by defining the (individual) residual/total retinal deviation value ratio for each case.

\section{Statistical analysis}

The data were entered into a Microsoft ${ }^{\circledR}$ Excel $^{\circledR}$ spreadsheet and analyzed using SPSS (version 15.0) statistical software. Measures of central tendencies, including means, standard deviations, and ranges were calculated by descriptive analysis. A repeated measure analysis of variance (ANOVA), paired samples test, and appropriate post hoc t-test comparisons were performed using the method described by Tukey. The appropriate mean square error from the analysis of variance, $P<0.05$, was accepted as statistically significant.

\section{Results}

98 eyes of 60 patients were included in the study. Mean age was 25.9 years $( \pm 8.4)$ in Group A, 29.4 years $( \pm 8.7)$ in Group B, 25.07 years $( \pm 4.5)$ in Group C, 23.3 years $( \pm 5.5)$ in Group D $(P=0.712)$. The female/male ratio was $15 / 10$ in Group A, 12/10 in Group B, 15/13 in Group C, and 14/9 in Group D.

A summary of mean baseline spectacle spheric power and mean cylinder and keratometric astigmatism is presented in Table 2. Total mean retinal deviations were $3.27 \mathrm{D}( \pm 3.24)$ in Group A, 4.37 D $( \pm 3.0)$ in Group B, $3.52 \mathrm{D}( \pm 2.2)$ in Group C, and 3.30 D $( \pm 1.7)$ in Group D $(P=0.458)$.

Mean spheric, cylindric and keratometric values in diopters according to the groups measured over contact lenses, after contact lens application are presented in Table 3.

The average percent corneal astigmatic neutralization from the contact lenses were $-52 \%( \pm 28 \%)$ in Group A, $-53 \%( \pm 26 \%)$ in Group B, $-94 \%( \pm 25 \%)$ in Group C, and $126 \%( \pm 16 \%)$ in Group D $(P=0.000)$. The minus sign represents a decrease in the contact lens surface cylinder compared with the original corneal surface power.

Means of the visual acuities corrected with glasses were $0.02 \log$ MAR $( \pm 0.04)$ in Group A, $0.005 \log$ MAR $( \pm 0.002)$ in Group B, 0.0 $\log$ MAR $( \pm 0.0)$ in Group C, and 0.0 logMAR $( \pm 0.0)$ in Group D $(P=0.065)$. Means of the visual acuities corrected with contact lenses were $0.02 \log$ MAR $( \pm 0.01)$ in Group A, $0.025 \log$ MAR $( \pm 0.04)$ in Group B, $0.015 \log \mathrm{MAR}( \pm 0.01)$ in Group $\mathrm{C}$, and $0.0 \log \mathrm{MAR}( \pm 0.0)$ in Group D $(P=0.106)$.

Residual mean retinal deviations after contact lens fitting were $0.04 \mathrm{D}( \pm 0.40)$ in Group A, $0.11 \mathrm{D}( \pm 0.53)$ in Group B, $0.26 \mathrm{D}( \pm 0.43)$ in Group C, and $0.20 \mathrm{D}( \pm 0.25)$ in Group D $(P=0.240)$. The average of the ratios of residual/total mean retinal deviation was: $0.25 \mathrm{D}( \pm 0.34)$ in Group A, $0.17 \mathrm{D}( \pm 0.21)$ in Group B, 0.12D $( \pm 0.07)$ in Group C, and $0.18( \pm 0.41)$ in Group D $(P=0.415)$.

During the statistical analysis, after soft toric lens application, spheric dioptres, cylindric and keratometric astigmatism, and retinal deviation decreased significantly in Groups A and $\mathrm{B}(P=0.0)$. In Group $\mathrm{C}$, spheric dioptres $(P=0.012)$ and spherical equivalent refraction $(P=0.0)$ decreased. While cylindric $(P=0.547)$ and keratometric $(P=0.286)$ astigmatism did not change significantly.

In Group D, spheric dioptres and spherical equivalent refraction $(P=0.0)$ and cylindric astigmatism $(P=0.045)$ decreased, while keratometric astigmatism $(P=170)$ did not change significantly, and astigmatic neutralization even increased.

Table 2 Spectacle spheric, cylindric, keratometric and retinal deviation mean values in diopters according to the groups before contact lens application

\begin{tabular}{|c|c|c|c|c|c|}
\hline & $\begin{array}{l}\text { Group A (toric }> \\
\text { I.25 D) }\end{array}$ & $\begin{array}{l}\text { Group B (toric } \\
0.75-1.25 \text { D) }\end{array}$ & $\begin{array}{l}\text { Group C (spheric } \\
0.75-1.25 \text { D) }\end{array}$ & $\begin{array}{l}\text { Group D (spheric } \\
<0.75 \text { D) }\end{array}$ & $P$ \\
\hline Age & $25.9 \pm 8.4$ & $29.4 \pm 8.7$ & $25.07 \pm 4.5$ & $23.3 \pm 5.5$ & 0.030 \\
\hline Gender (Female/Male) & $15 / 10$ & $12 / 10$ & $15 / 13$ & $14 / 9$ & 0.712 \\
\hline Mean spheric power $D$ & $-2.48 \pm 3.14$ & $-3.08 \pm 3.03$ & $-3.25 \pm 2.1$ & $-3.13 \pm 1.8$ & 0.361 \\
\hline Mean cylinder D & $-1.7 \pm 0.37$ & $-1.03 \pm 0.22$ & $-0.54 \pm 0.44$ & $-0.33 \pm 0.21$ & 0.000 \\
\hline Keratometric astigmatism D & $-1.46 \mathrm{D} \pm 0.24$ & $-1.13 \mathrm{D} \pm 0.43$ & $-1.03 \pm 0.2$ & $-0.40 \pm 0.22$ & 0.000 \\
\hline Total mean retinal deviations & $3.27 \pm 3.24$ & $4.37 \pm 3.0$ & $3.52 \pm 2.2$ & $3.30 \pm 1.7$ & 0.458 \\
\hline
\end{tabular}


Table 3 Spheric, cylindric, keratometric and retinal deviation mean values in diopters, astigmatic neutralization and visual acuity (Snellen lines) according to the groups after contact lens application

\begin{tabular}{|c|c|c|c|c|c|}
\hline & $\begin{array}{l}\text { Group A (toric }> \\
\text { I.25 D) }\end{array}$ & $\begin{array}{l}\text { Group B (toric } \\
0.75-1.25 \text { D) }\end{array}$ & $\begin{array}{l}\text { Group C (spheric } \\
0.75-1.25 \text { D) }\end{array}$ & $\begin{array}{l}\text { Group D (spheric } \\
<0.75 \text { D) }\end{array}$ & $P$ \\
\hline Sphere & $0.25( \pm 0.4 I)$ & $0.20( \pm 0.55)$ & $0.70( \pm 0.4)$ & $0.06( \pm 0.28)$ & 0.540 \\
\hline Cylinder & $-0.57( \pm 0.3 \mathrm{I})$ & $-0.59( \pm 0.34)$ & $0.50( \pm 0.45)$ & $0.22( \pm 0.21)$ & 0.002 \\
\hline Keratometric astigmatism & $0.74( \pm 0.35)$ & $0.62( \pm 0.38)$ & $-0.97( \pm 0.34)$ & $-0.49( \pm 0.33)$ & 0.000 \\
\hline Astigmatic neutralization & $52 \%( \pm 28 \%)$ & $53 \%( \pm 26 \%)$ & $94 \%( \pm 25 \%)$ & $126 \%( \pm 16 \%)$ & 0.000 \\
\hline Visual acuity (logMAR) & $0.02( \pm 0.01)$ & $0.025( \pm 0.04)$ & $0.015( \pm 0.01)$ & $0.0( \pm 0.0)$ & 0.106 \\
\hline $\begin{array}{l}\text { Residual mean retinal } \\
\text { deviations }\end{array}$ & $0.04( \pm 0.40)$ & $0.11( \pm 0.53)$ & $0.26( \pm 0.43)$ & $0.20( \pm 0.25)$ & 0.240 \\
\hline $\begin{array}{l}\text { Residual/Total mean retinal } \\
\text { deviations }\end{array}$ & $0.25( \pm 0.34)$ & $0.17( \pm 0.21)$ & $0.12( \pm 0.07)$ & $0.18( \pm 0.41)$ & 0.415 \\
\hline
\end{tabular}

Among the different lens types used, in Groups A, B, and $\mathrm{D}$, we did not observe statistical difference for spheric, cylindric dioptres, keratometric astigmatism, or retinal deviation, while in Group C, we observed significant difference only for the ratios of residual/total mean retinal deviation $(P=0.008)$.

In our study, less than two rows of spectacle-contact lens difference for visual performance and less than $0.50 \mathrm{D}$ of retinal deviation as objective criteria, were accepted as a successful response. 100\% of eyes in Groups A, B, and $\mathrm{D}$ and $96 \%$ of eyes in Group $\mathrm{C}$ had 2.0 or less line loss in visual acuity $(P>0.05)$. All these patients had low residual mean retinal deviation values $(>0.50 \mathrm{D})$. The percentage of patients having less than $0.50 \mathrm{D}$ of residual retinal deviation was $80 \%$ in Group A, 95\% in Group B, 78\% in Group C, and $95 \%$ in Group D (Table 4).

When we considered less than one row of spectaclecontact lens difference for visual performance in Groups A, $\mathrm{B}, \mathrm{C}$, and D, success percentages were $80 \%, 100 \%, 78.2 \%$, and $82 \%$ respectively.

When we compared our patients with low astigmatism between $0.75-1.25 \mathrm{D}$ in Groups $\mathrm{B}$ and $\mathrm{C}$ using toric and spheric lenses respectively, we observed significant difference in residual corneal astigmatism $(P=0.005)$ and astigmatic neutralization $(P=0.048)$. Although not significant statistically, visual success rate $(<2$ line loss) was lower in Group C (96\%) than Group B $(100 \%)(P=0.674)$, and residual retinal deviation success $(<0.50 \mathrm{D})$ was lower in Group C (78\%) than Group B $(95 \%)(P=0.551)$. The astigmatic neutralization value was $53 \%( \pm 26 \%)$ in Group B and $94 \%( \pm 25 \%)$ in Group C.

The evaluation of topographic data showed that, after toric lens application, the astigmatism on the anterior surface was neutralized and the bow tie appearance was dispersed through the periphery depending on the residual astigmatism in Groups A and B. However, after spheric lens application in Groups $\mathrm{C}$ and D, bow tie appearance was projected nearly equally on the anterior surface topography, compared to values obtained before contact lens application (Figures 3-4).

\section{Discussion}

The dioptric power of a soft contact lens on the eye is a function of its off-eye power, lens flexion on the eye, lens hydration and corneal topography. Though patient satisfaction and subjective visual data point out important clues, confirming these data more objectively by autorefraction and topography will be useful in our overall evaluation. The success of the fitting technique can be assessed in consideration of manifest refraction with the toric and spheric soft contact lens in situ on the eye. We calculated mean retinal deviation in order to predict loss of visual acuity using residual refractive error. Mean retinal deviation is a geometric optical calculation method that describes the amount of defocus at the plane of the retina and combines the three components of spheric

Table 4 Visual success and residual retinal deviation success rates according to the groups

\begin{tabular}{lllll}
\hline & $\begin{array}{l}\text { Group A (toric }> \\
\text { I.25 D) }\end{array}$ & $\begin{array}{l}\text { Group B (toric } \\
\mathbf{0 . 7 5}-1.25 \text { D) }\end{array}$ & $\begin{array}{l}\text { Group C (spheric } \\
\mathbf{0 . 7 5}-1.25 \text { D) }\end{array}$ & $\begin{array}{l}\text { Group D (spheric } \\
<\mathbf{0 . 7 5} \text { D) }\end{array}$ \\
\hline $\begin{array}{l}\text { Visual success rates } \\
(<2 \text { line loss) }\end{array}$ & $100 \%(25 / 25$ eyes) & $100 \%(22 / 22$ eyes $)$ & $96 \%(27 / 28$ eyes $)$ & $100 \%(23 / 23$ eyes $)$ \\
$\begin{array}{l}\text { Residual retinal deviation } \\
\text { success ( }<0.50 \text { D) }\end{array}$ & $80 \%(20 / 25$ eyes) & $95 \%(21 / 22$ eyes $)$ & $78 \%(22 / 28$ eyes $)$ & $95 \%(22 / 23$ eyes $)$ \\
\hline
\end{tabular}

Notes: Less than two rows of spectacle-contact lens difference during visual acuity measurement and residual retinal deviation less than $0.50 \mathrm{D}$ was accepted as successful. 


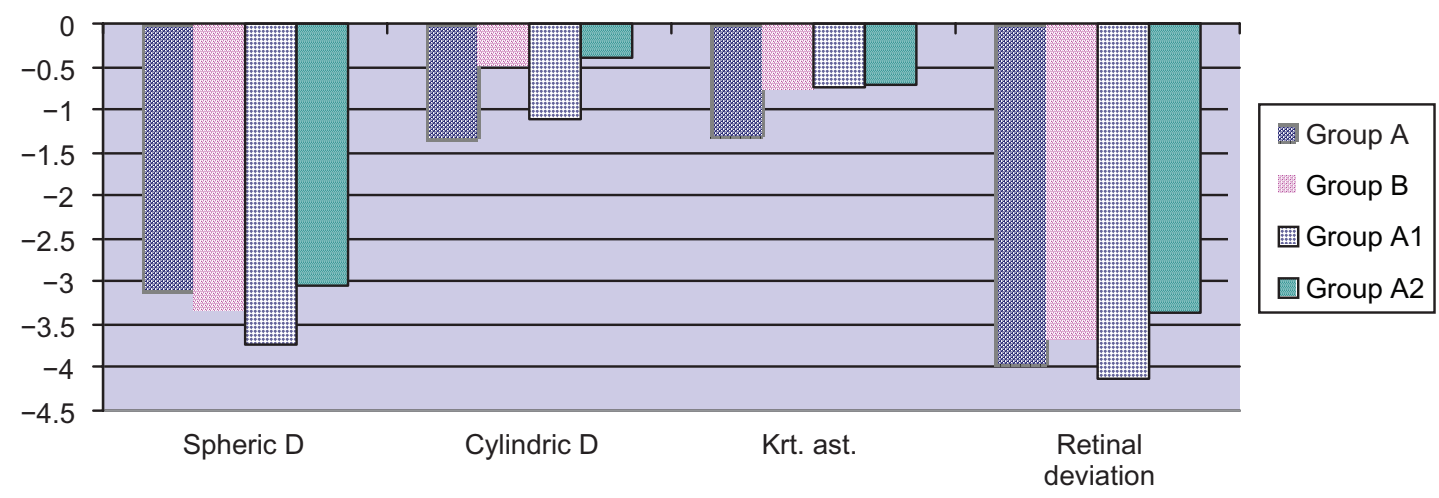

Figure I Spheric, cylindric, keratometric and retinal deviation mean values in diopters according to the groups before contact lens application.

power, cylindric power and axis into a single dioptric measure by taking the mean of the absolute values of the principal meridians. Since this value gives us deviation from the retinal plane; it should not be mixed up with spherical equivalent. Spherical equivalent specifies the mean point between the main meridians instead of retinal deviation. The relationship between visual acuity loss and optical errors was used to predict the effect on visual acuity. This method was previously applied to a sample of 457 Focus $^{\circledR}$ toric soft contact lenses. It found that $83.5 \pm 1.7 \%$ of the lenses were accurate enough to deliver one line or less of loss in visual acuity. ${ }^{12}$

There is no appreciable neutralization of corneal astigmatism with spherical soft lenses and, possibly, there is an increase in surface irregularity. A spherical contact lens used for a patient with less than $0.75 \mathrm{D}$ cylinder led to a $21 \%-24 \%$ increase in the contact lens surface cylindrical power compared to the original corneal surface power, while a spherical contact lens applied on a toric cornea led to $89 \%$ increase in corneal cylindric value. Toric contact lenses fitted into toric corneas led to a $34 \%-38 \%$ decrease in the corneal cylindric dioptres. ${ }^{13}$

Flexure of toric hydrogel contact lenses is explained by the Linear Regression Hypothesis, which implies that partial flexure due to different meridians might lead to the minus tear lens formation and residual refractive astigmatism. ${ }^{14}$ McCarey and co-workers have observed that the toric soft contact lens neutralized the cylinder component $37 \%$ by topography and $57 \%$ by manifest refraction. ${ }^{13}$ In this study, our results are in agreement with previous studies: corneal astigmatic neutralization values were $-52 \%( \pm 28 \%)$ to $-53 \%( \pm 26 \%)$ for soft toric lenses in Groups A to B and $-94 \%( \pm 25 \%)$ to $126 \%( \pm 16 \%)$ for soft spheric lenses in Groups C and D.

The anterior surface of the eye has the largest refractive index in the optical system. When a toric lens is applied, its anterior surface becomes most important refractive surface. Theoretically, soft toric contact lenses are manufactured for neutralization of ocular surface toricity. That is why in situ topographic maps show relatively spheric or equivalent or opposite power anterior surface toricity in residual astigmatism. ${ }^{7,13}$ Corneal topography is a beneficial method for the objective evaluation of spheric and toric lens behaviour in situ, such as the effect of soft lens flexure on the eye, lid effect, optical quality, and lens cleaning techniques. ${ }^{15}$ Topographic evaluation is as important as flourescein pattern

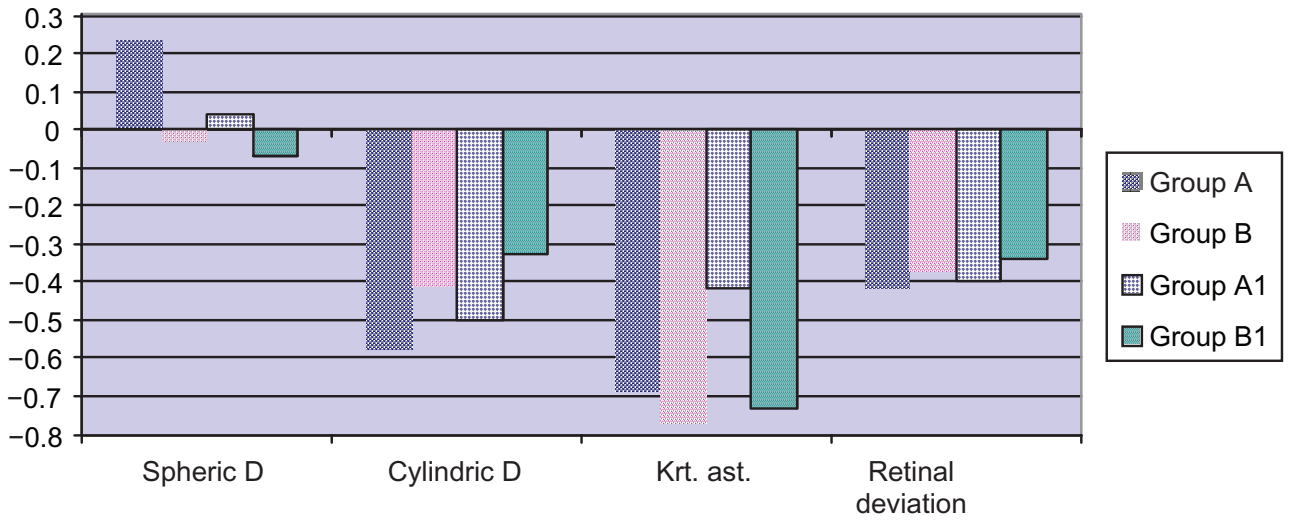

Figure 2 Spheric, cylindric, keratometric and retinal deviation mean values in diopters according to the groups after contact lens application. 
A

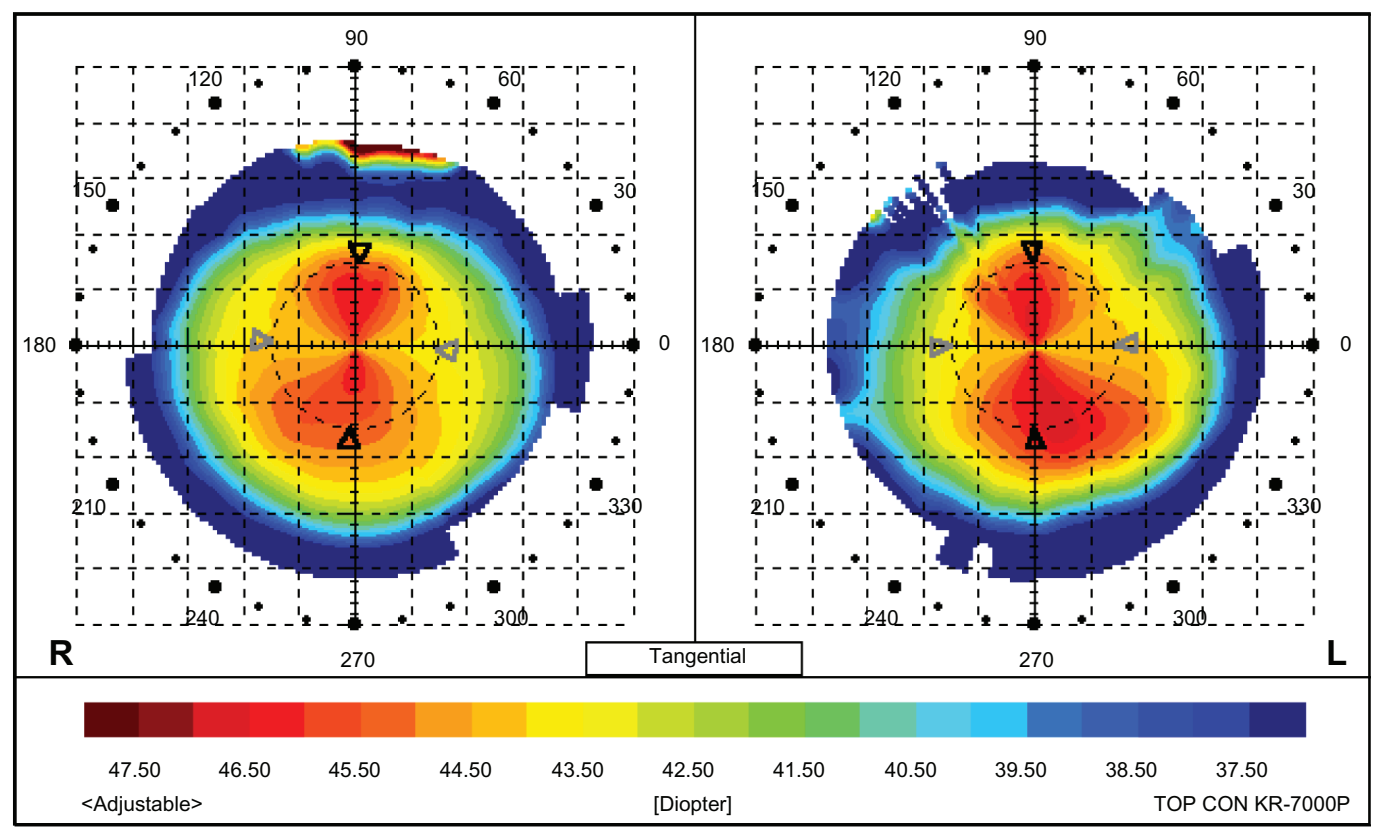

B

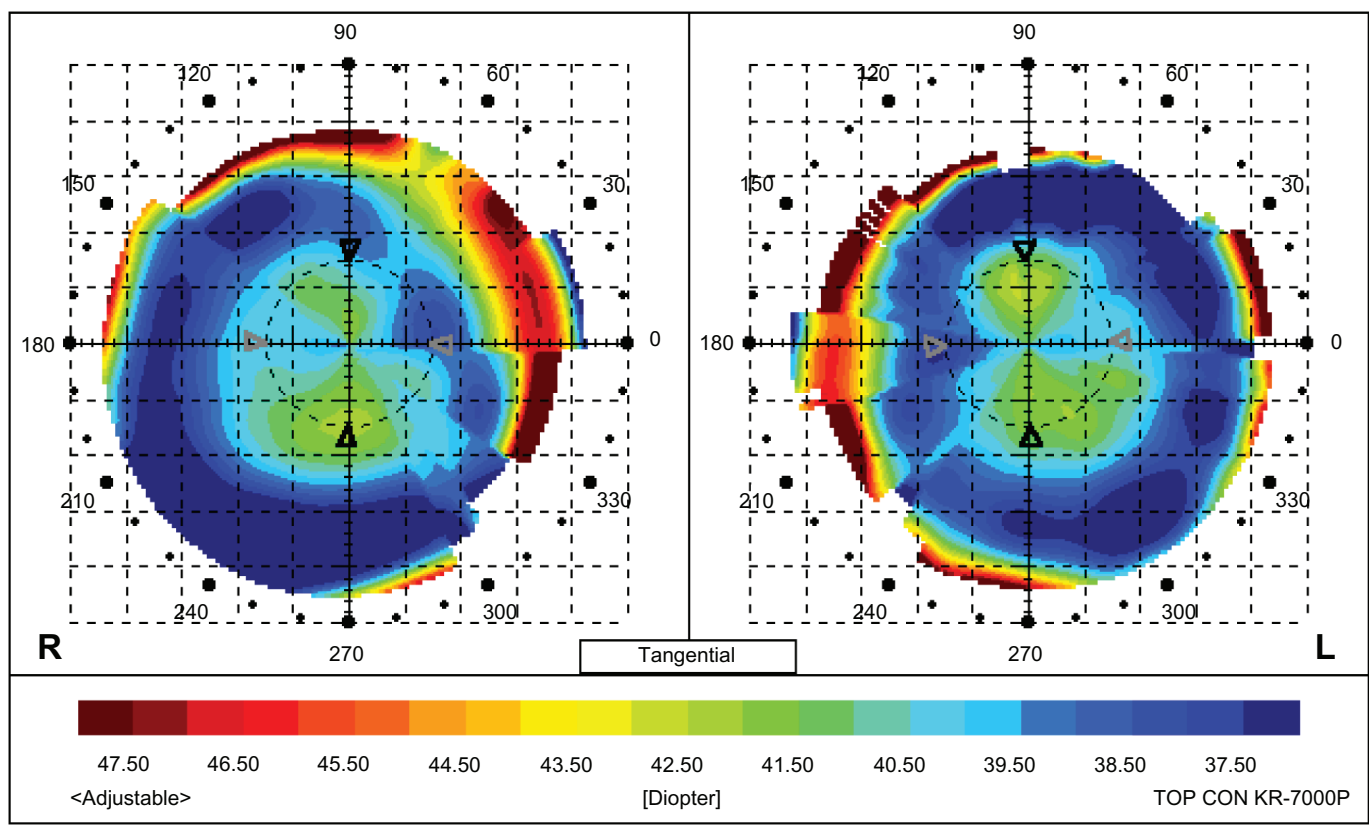

Figure 3 A) Color mapping without contact lens in a Group B patient. B) Color mapping of the same patient after soft toric lens fitting.

evaluation in gas permeable contact lenses, as it can also point out manufacturing faults or surface irregularities of lenses. Soft lenses drape the cornea, and keratometry may allow us to check the central bearing area of contact lenses. Significant correlations between toricity of the front surface of the contact lens and that of the cornea has been observed by means of keratometry and photoelectric keratoscopy. ${ }^{16}$

We used a placido disc-based corneal mapping system and observed that toric lenses caused central neutralization and dispersion of bow tie appearance through the periphery, which led to the formation of an island shape. On the other hand, with soft spheric lenses, the previous bow tie appearance persisted centrally, which implied that the neutralization process was inadequate.

An often-quoted strategy for correcting low degrees of astigmatism with soft lenses is to increase the thickness of the lens or use a higher modulus material, considering that a thicker or stiffer lens may drape less on the cornea and so mask more astigmatism. Hovewer, no significant effect of lens thickness has been reported for the majority of patients. ${ }^{17-19}$ Research by Cho and Woo ${ }^{17}$ examined whether thicker or thinner lenses provided better acuity with high- and 


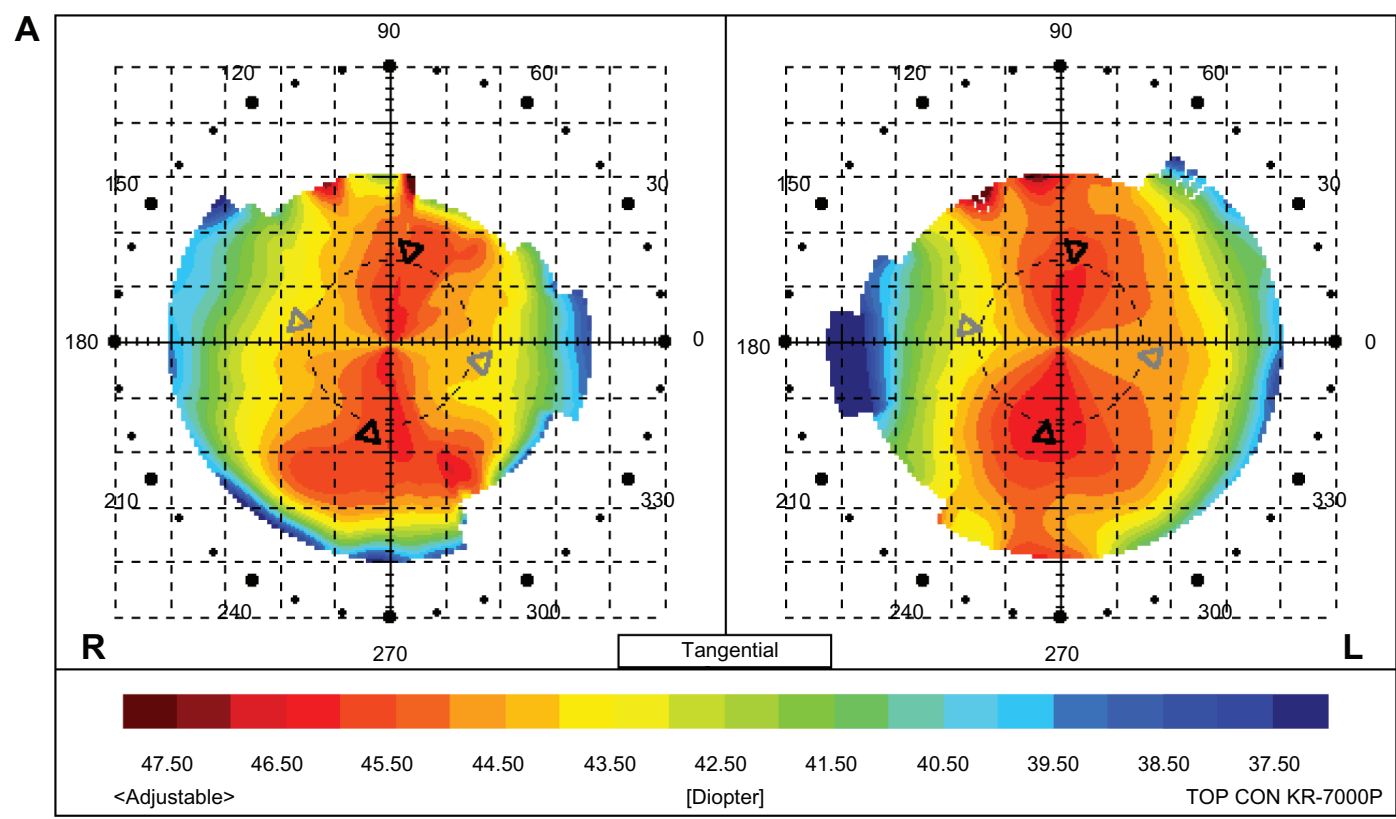

B

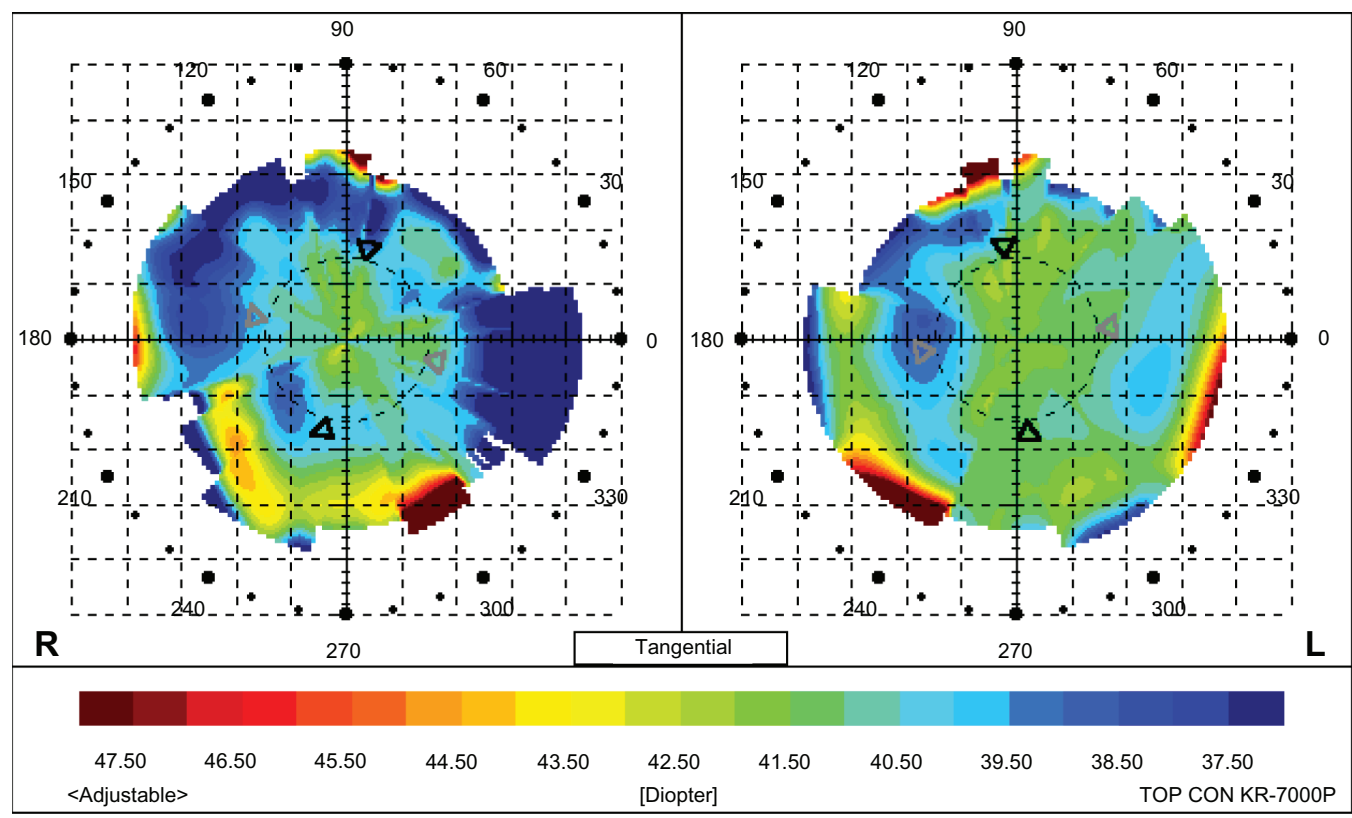

Figure 4 A) Color mapping of a patient before soft toric lens fitting. B) Color mapping of the same patient after soft toric lens fitting.

low-contrast $\log$ MAR charts. Using lenses that have center thicknesses of $0.06 \mathrm{~mm}$ and $0.12 \mathrm{~mm}$, they noted that the thicker lenses provided better acuity, though this difference was not statistically significant. Likewise, a higher modulus spherical silicone hydrogel material has been shown to have no significant impact on the amount of astigmatism masked when compared to a hydrogel soft contact lens..$^{20}$ In this study, we used spheric hydrogel contact lenses with center thicknesses between $0.08 \mathrm{~mm}$ and $0.1 \mathrm{~mm}$, and similar to other reports, lens thickness had no influence on the amount of astigmatism masked.
There remains some disagreement as to when to fit soft toric lenses. Dabkoski et $\mathrm{al}^{21}$ found that low to moderate myopes with low astigmatism ( $0.75 \mathrm{DC}$ to $1.25 \mathrm{DC})$ had significantly better acuity with toric lenses than with the spherical equivalent. Richdale et $\mathrm{al}^{22}$ evaluated the acuity of myopic astigmats wearing both soft spherical and toric lenses from four manufacturers. For these patients, whose astigmatism was between $-1.25 \mathrm{DC}$ and $-2.00 \mathrm{DC}$, soft torics improved their acuity by about two Snellen lines in both bright and dim light compared to spherical lenses. For low-cylinder patients, the bright light results were 
more modest, yielding only a few letters more, but in dim light their acuity improved by just over one line. Recently, aspheric soft lenses have been promoted for the correction of low levels of astigmatism. Morgan et $\mathrm{al}^{23}$ evaluated high- and low-contrast acuity with spectacles, aspheric soft lenses and toric soft lenses in patients with refractive astigmatism of $-0.75 \mathrm{DC}$ or $-1.00 \mathrm{DC}$. They used variable pupil sizes to simulate different lighting conditions. They found that high-contrast and low-contrast visual acuity are superior with toric soft contact lenses and spectacles versus aspheric soft contact lenses for larger pupils by approximately a half-line or more, which is considered to be clinically significant. Superior vision can be achieved for low astigmatic contact lens wearers using toric soft rather than aspheric soft contact lenses.

In our study, less than two rows of spectacle - contact lens difference for visual performance and less than $0.50 \mathrm{D}$ of retinal deviation, as objective criteria, were accepted as a successful response. For the highly astigmatic Group A $(>1.25 \mathrm{D})$, residual mean retinal deviation success was low (80\%), but visual success rates were encouraging (100\%) after soft toric lens application.

When we compared our patients with low astigmatism (between 0.75-1.25 D) in Groups B and C using toric and spheric lenses respectively, we observed significant difference in residual corneal astigmatism $(P=0.005)$ and astigmatic neutralization $(P=0.048)$, Although not significant statistically, visual success rates $(<1$ line loss) was lower in Group C $(96 \%)$ than Group B $(100 \%)(P=0.674)$, and residual retinal deviation success $(<0.50 \mathrm{D})$ was lower in Group C $(78 \%)$ than Group B $(95 \%)(P=0.551)$, and astigmatic neutralization value was $53 \%( \pm 26 \%)$ in Group B and $94 \%$ $( \pm 25 \%)$ in Group C.

As a conclusion, in this study, visual acuity and residual retinal deviation remained between tolerable limits with the use of toric and spheric contact lenses. Spherical lenses failed to mask corneal toricity during topography and even increased the corneal astigmatism, even in low astigmatism, while toric lenses caused central neutralization and decrease in corneal cylinder. Toric lenses should be preferred in patients with low astigmatism.

Clinical Ophthalmology

\section{Publish your work in this journal}

Clinical Ophthalmology is an international, peer-reviewed journal covering all subspecialties within ophthalmology. Key topics include: Optometry; Visual science; Pharmacology and drug therapy in eye diseases; Basic Sciences; Primary and Secondary eye care; Patient Safety and Quality of Care Improvements. This journal is indexed on Submit your manuscript here: http://www.dovepress.com/clinical-ophthalmology-journal

\section{Disclosure}

The authors disclose no conflicts of interest.

\section{References}

1. Holden BH. The principles and practices of correcting astigmatism with soft contact lenses. Ast J Optom. 1995;58:279-299.

2. Morgan P, Efron N. Trends in UK contact lens prescribing 1999. Optician. 1999;217(5700):43-44.

3. Kanpolat A, Oral D. Types of contact lenses applied in astigmatic cases. Contactologia. 2000;22:42-45.

4. Morgan P, Efron N, Woods C, et al. International contact lens prescribing in 2004. CL Spectrum. 2005;20(1):34-37.

5. Bennett AG. Power changes in soft lenses due to bending. Ophthalmic Optician. 1976;16:939-945.

6. Bennet ES, Blanc P, Remba MR. Correction of astigmatism. In: Henry VA, editor. Clinical Manual of Contact Lenses. Philedelphia: Lippincott Williams \& Wilkins; 2000. p. 376-390.

7. McCarey BE, Amos CF.Topographic evaluation of toric soft contact lens correction. CLAO J. 1994;20:261-265.

8. Hall DK, Werd JA, Edmondson W. Spectacles and custom toric hydrogel contact lenses: A comparison of vision. JAOA.1994;65(11):783-787.

9. Cabrera JV,Rodrigues JB. Vision with disposable toric contact lenses and daily wear toric contact lenses. Ophthalmic Phsiol Opt. 1998 Jan:66-74.

10. Hickson-Curran S, Dias L. Toric soft contact lenses: Where are we now? Optician. 2006;231(6041):14-16.

11. Young G. Evaluation of soft contact lens fitting characteristics. Optom Vis Sci. 1996;73:247-254.

12. Poyor RE, Roberts SR, Schvallic ID. Soft toric lens power accuracy and reproducibility. CLAO J. 1995;21(3):163-168.

13. McCarey BE, Amos CF, Taub LR. Surface topography of soft contact lenses for neutralizing corneal astigmatism. CLAO J. 1993;19(2):114-120.

14. Weissman BA. Theoretical optics of toric hydrogel contact lenses. Am J Optom Physiol Opt. 1986;63:536-538.

15. Maeda N, Klyce SD, Smolek MK, Hamano H, et al. Videokeratography for quantitative surface analysis of used soft contact lenses. Jpn $J$ Ophthalmol. 1997;41(4):235-239.

16. Tomlinson A. Contact lens and corneal topography with wear of the Soflens. Am J Optom Physiol Opt. 1976;53(11):727-734.

17. Cho PC, Woo GC. Vision of low astigmats through thick and thin lathe-cut soft contact lenses. Contact Lens Anterior Eye. 2001;24(4):153-160.

18. Harris MG, Lau S, Ma H, Tuan J. Do disposable contact lenses mask astigmatism? Optical Prism. 1996;14(2):44-46.

19. Bernstein PR, Gundel RE, Rosen JS. Masking corneal toricity with hydrogels: Does it work? Int Contact Lens Clinic. 1991;60:728-731.

20. Edmondson L, Edmondson W II, Price R. Masking astigmatism: Ciba Focus Night and Day vs Focus Monthly. Optom Vis Sci. 2003;80(12):184.

21. Dabkowski JA, Roach MP, Begley CG. Soft toric versus spherical contact lenses in myopes with low astigmatism. Int Contact Lens Clin. 1992;19:252-256.

22. Richdale K, Berntsen DA, Mack CJ, Merchea MM, Barr JT. Visual acuity with spherical and toric soft contact lenses in low- to moderateastigmatic eyes. Optom Vis Sci. 2007;84(10):969-975.

23. Morgan PB, Efron SE, Efron N, Hill EA. Inefficacy of aspheric soft contact lenses for the correction of low levels of astigmatism. Optom Vis Sci. 2005;82(9):823-828.

\section{Dovepress}

PubMed Central and CAS, and is the official journal of The Society of Clinical Ophthalmology (SCO). The manuscript management system is completely online and includes a very quick and fair peer-review system, which is all easy to use. Visit http://www.dovepress.com/ testimonials.php to read real quotes from published authors. 